\title{
EFEITO DE DIFERENTES PERÍODOS DE IRRIGAÇÃO NO DESENVOLVIMENTO, PRODUÇÃO E QUALIDADE DE SEMENTES NA CULTURA DO MILHO (Zea mays L.)
}

\author{
JOÃO A. GALBIATTI ${ }^{1}$, MAURÍCIO J. BORGES ${ }^{2}$, LARA F. BUENO ${ }^{3}$, ANICE GARCIA ${ }^{4}$, \\ ROBERVAL D. VIEIRA ${ }^{5}$
}

\begin{abstract}
RESUMO: O presente trabalho foi realizado em área demonstrativa de irrigação do Departamento de Engenharia Rural da Faculdade de Ciências Agrárias e Veterinárias, da Universidade Estadual Paulista (FCAV/UNESP), Jaboticabal - SP, tendo como objetivo avaliar os efeitos da deficiência hídrica no desenvolvimento da planta, na produção e na qualidade fisiológica de sementes da cultura do milho (Zea mays L.). O delineamento experimental foi o inteiramente casualizado, com os tratamentos em esquema fatorial $2 \times 3$, com quatro repetições. Os tratamentos consistiram da utilização de sementes de milho híbrido BR201 e DINA-70, com três períodos de irrigação: 1) durante todo o ciclo; 2) após o período vegetativo (após a emissão da 12 $1{ }^{\mathrm{a}}$ folha), e 3) até 20 dias após o florescimento (antes do período de enchimento dos grãos). Concluiu-se que a deficiência hídrica durante o período vegetativo (irrigação após a emissão da 12a folha) foi a mais prejudicial à cultura e à produção; essa deficiência hídrica não afetou a qualidade fisiológica das sementes produzidas, e o híbrido DINA-70 apresentou melhores resultados para os parâmetros fisiológicos e de produção que o híbrido BR201.
\end{abstract}

PALAVRAS-CHAVE: estresse hídrico, análise de crescimento, manejo da água.

\section{EFFECT OF DIFFERENT IRRIGATION PERIODS IN THE DEVELOPMENT, YIELD AND SEEDLING QUALITY IN THE MAIZE (Zea mays L.) CROP}

SUMMARY: The experiment was conducted at the experimental area of the Rural Engineering Department of the Faculdade de Ciências Arárias e Veterinárias, Câmpus de Jaboticabal, Universidade Estadual Paulista (FCAV/UNESP), Brazil. The aim of this work was to verify the effect of the water deficit on maize (Zea mays L.) crop during vegetative growth, in its production and physiological seed quality. A completely randomized statistical design with four replications, in a $3 \times 2$ factorial array was used. The treatments consisted of three irrigation periods (during maize growth; after the emission of the $12^{\text {th }}$ leaf, and 20 days after flowering time), using cross hybrids seedling BR201 and DINA-70. Results indicated that the water deficit on the vegetative growth (irrigation only after the emission of the $12^{\text {th }}$ leaf) was the most harmful to maize plants and their production; the water deficit didn't affect the physiological seed quality. The physiological and production parameters were better in the cross hybrid DINA70 than in the hybrid BR201.

KEYWORDS: hidric stress, growth analysis, water management.

\footnotetext{
${ }^{1}$ Eng ${ }^{0}$ Agrônomo, Prof. Titular, Departamento de Engenharia Rural, Faculdade de Ciências Agrárias e Veterinárias - UNESP, Jaboticabal - SP, Fone: (0XX16) 3209.2637, e-mail: galbi@fcav.unesp.br

${ }^{2}$ Eng $^{\mathrm{O}}$ Agrônomo, Doutorando em Agronomia, FCAV/UNESP, Jaboticabal - SP, Chefe do Depto. de Agricultura e Abastecimento da Prefeitura Jaboticabal - SP, Fone: (0XX16) 3209.2637, e-mail:_mjborges@ fcav.unesp.br

${ }^{3}$ Eng ${ }^{\underline{a}}$ Agrônoma, Mestranda em Ciência do Solo, FCAV/UNESP, Jaboticabal - SP.

${ }^{4}$ Eng ${ }^{\mathrm{a}}$ Agrônoma, Doutora pela FCAV/UNESP, Jaboticabal - SP.

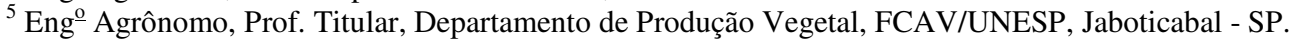

Recebido pelo Conselho Editorial em: 27-2-2003

Aprovado pelo Conselho Editorial em: 4-2-2004
}

Eng. Agríc., Jaboticabal, v.24, n.2, p.301-308, maio/ago. 2004 


\section{INTRODUÇÃO}

Entre as culturas de interesse econômico para o Brasil, destaca-se a de milho (Zea mays L.), a qual assume relevante papel socioeconômico e constitui-se em matéria-prima impulsionadora de diversos complexos agroindustriais (FANCELLI \& DOURADO-NETO, 2000). Essa é uma cultura de rendimento muito variável, em função de déficits hídricos causados por variações climáticas, cujo efeito depende da intensidade, época e duração em relação ao ciclo de crescimento e desenvolvimento da planta (JURGENS et al., 1978 ; CUNHA \& BERGAMASCHI, 1992).

À medida que se desenvolvem estratégias de irrigação, torna-se importante conhecer o efeito da deficiência hídrica nos estádios de desenvolvimento das plantas. Na planta, tanto o crescimento quanto o desenvolvimento e a translocação de fotoassimilados encontram-se ligados à disponibilidade hídrica do solo (FANCELLI \& DOURADO-NETO, 2000). No processo de fotossíntese, a falta d'água influencia na deposição de matéria seca, limitando a disponibilidade de $\mathrm{CO}_{2}$ e os processos de elongação celular (EMBRAPA, 1993).

Diversos autores citados por BERGONCI et al. (2001) sugerem que plantas deficientes em água podem apresentar insuficiência de assimilados para manter o crescimento de todos os zigotos formados, além de apresentarem redução no tempo da polinização pela inibição do alongamento do estilete e retardamento na emergência dos estigmas. $O$ desenvolvimento e o peso dos grãos podem ser afetados pela redução da fotossíntese, pois a menor produção de carboidratos implica menor quantidade de matéria seca nos grãos (EMBRAPA, 1993).

Segundo FORNASIERI (1992), em condições de água facilmente disponível às plantas, a cultura do milho apresenta um consumo médio de água de $573 \mathrm{~mm}$, mostrando grandes necessidades diárias no período compreendido entre o pendoamento e o espigamento. Isso faz com que essa cultura seja muito sensível ao déficit hídrico durante as fases fenológicas de florescimento e início da formação de grãos.

BERGONCI et al. (2001), relacionando o déficit hídrico com a redução do número de grãos por espiga e por metro quadrado, concluíram que o déficit hídrico que ocorre no período vegetativo interfere pouco no rendimento, pois não afeta significativamente o número de grãos por espiga. SILVA (2000) observou que o estresse hídrico, logo após o estabelecimento do número de grãos, reduziu o período de enchimento de grãos, mas não alterou a taxa de acúmulo de matéria seca, tanto no endosperma quanto no embrião.

NESMITH \& RITCHIE (1992) consideram que o número de grãos é o principal componente responsável pela produção e, coincidindo com estudos de JURGENS et al. (1978), identificaram perdas de produção por deficiências hídricas durante o período de enchimento de grãos. CHOTENA et al. (1980) observaram que a deficiência hídrica moderada reduziu a taxa de germinação das sementes, mas não influenciou no seu vigor.

Em função dessas considerações, realizou-se o presente trabalho com o objetivo de verificar os efeitos do estresse por deficiência hídrica, em diferentes fases do ciclo do milho, sobre o desenvolvimento da planta, a produção e a qualidade fisiológica da semente.

\section{MATERIAL E MÉTODOS}

Este trabalho foi conduzido em área experimental de irrigação da Faculdade de Ciências Agrárias e Veterinárias (FCAV/UNESP), Câmpus de Jaboticabal. O delineamento experimental foi o inteiramente casualizado, em esquema fatorial 3 x 2 (três períodos de irrigação x dois híbridos de milho), perfazendo um total de seis tratamentos, com quatro repetições (Tabela 1). Cada parcela compreendeu $36 \mathrm{~m}^{2}$, constituindo-se de cinco linhas de nove metros de comprimento, espaçadas de $80 \mathrm{~cm}$ entre linhas e $25 \mathrm{~cm}$ entre plantas. No caso de área foliar e matéria seca, foram realizadas cinco avaliações durante o experimento e utilizou-se, para efeito de análise estatística, o esquema de parcelas subdivididas no tempo. 
TABELA 1. Tratamentos empregados no experimento.

\begin{tabular}{ccccccc}
\hline \multirow{2}{*}{ Características } & \multicolumn{7}{c}{ Tratamentos } \\
\cline { 2 - 7 } & T1 & T2 & T3 & T4 & T5 & T6 \\
\hline Irrigação* & I1 & I1 & I2 & I2 & I3 & I3 \\
Híbrido & BR 201 & DINA-70 & BR 201 & DINA-70 & BR 201 & DINA-70 \\
\hline
\end{tabular}

* I1) durante todo o ciclo; I2) a partir da 12를 folha; I3) até 20 dias após o florescimento.

Os solos nos tratamentos T3, T4, T5 e T6, quando não estavam sob irrigação, foram protegidos com um filme plástico preto para evitar interferências pluviométricas. $\mathrm{O}$ filme foi estendido entre linhas e grampeados uns aos outros, cobrindo a superfície da parcela de modo similar ao sistema usado por VIEIRA et al. (1992).

A irrigação foi realizada por aspersão, com base na evaporação do tanque Classe A, aplicando-se o coeficiente de uso consuntivo $\left(\mathrm{K}_{\mathrm{c}}\right)$ do milho (DOORENBOS \& PRUITT, 1984). Foram utilizados aspersores ZE-30D da Asbrasil, com bocais de 4,5 x 5,5 mm de diâmetro, espaçados de 18 x $18 \mathrm{~m}$, operados com $310^{5} \mathrm{~Pa}$ de pressão de serviço e precipitação de $10 \mathrm{~mm} \mathrm{~h}^{-1}$.

A adubação foi feita por ocasião da semeadura com base na análise do solo (Tabela 2) e nas recomendações da EMBRAPA (1993), na dosagem correspondente a $150 \mathrm{~kg} \mathrm{ha}^{-1}$ da fórmula de 4-20-20.

TABELA 2. Dados de análise química do solo antes da instalação do experimento.

\begin{tabular}{ccccccccccc}
\hline \multirow{2}{*}{ Análise } & $\begin{array}{c}\mathrm{P}^{2} \text { resina } \\
\mathrm{Mg} \mathrm{L}^{-1}\end{array}$ & $\begin{array}{c}\mathrm{M} . \mathrm{O} . \\
\%\end{array}$ & $\begin{array}{c}\mathrm{pH} \\
\mathrm{em} \mathrm{CaCl}_{2}\end{array}$ & $\begin{array}{c}\mathrm{K} \\
--------------\end{array}$ & $\begin{array}{c}\mathrm{Ca} \\
\mathrm{meq}\end{array}$ & $\begin{array}{c}\mathrm{H}+\mathrm{Al} \\
\mathrm{mL}^{-1}\end{array}$ & $\begin{array}{c}\mathrm{SB} \\
-------------\end{array}$ & $\mathrm{T}$ & $\mathrm{V}$ \\
\hline Valores & 30 & 2,6 & 5,5 & 0,32 & 2,8 & 1,3 & 2,5 & 4,45 & 6,92 & 6,5 \\
\hline
\end{tabular}

A semeadura foi efetuada manualmente no mês de abril, usando-se 15 sementes por metro e o desbaste foi realizado aos 25 dias após a semeadura, mantendo-se quatro plantas por metro linear. Um mês após a semeadura, aplicaram-se manualmente $100 \mathrm{~kg} \mathrm{ha}^{-1}$ de uréia em cobertura ao lado das linhas de milho.

No momento da semeadura, a água no solo estava retida a uma tensão de $-2,810^{4} \mathrm{~Pa}$, sendo a capacidade de campo para esse solo igual a $-2,010^{4} \mathrm{~Pa}$.

Nas parcelas, exceto nas que estavam cobertas com o filme plástico, foram realizadas capinas manuais aos 20 e aos 40 dias após a semeadura e, com um pulverizador costal, foi aplicado o inseticida monocrotophós (Azodrim) na concentração de $45 \mathrm{~mL}$ p.c./20 L de água para controle da lagarta-docartucho (Spodoptera frugiperda).

Os parâmetros fisiológicos das plantas foram avaliados em cinco períodos (Tabela 3), sendo os três primeiros no período vegetativo (aos $23 ; 39$ e 51 d.a.e.), o quarto no florescimento (aos 67 d.a.e.) e o quinto no enchimento de sementes (aos 107 d.a.e.).

TABELA 3. Etapas da determinação dos parâmetros fisiológicos das plantas de milho.

\begin{tabular}{lccccc}
\hline \multicolumn{1}{c}{ Etapas da Avaliação } & $1^{\underline{a}}$ & $2^{\underline{a}}$ & $3^{\underline{a}}$ & $4^{\underline{a}}$ & $5^{a^{\underline{a}}}$ \\
\hline Período fisiológico* & $\mathrm{V}$ & $\mathrm{V}$ & $\mathrm{V}$ & $\mathrm{F}$ & $\mathrm{E}$ \\
Dias após a emergência (d.a.e.) & 23 & 39 & 51 & 67 & 107 \\
\hline
\end{tabular}

$\mathrm{V}$ - vegetativo; F - florescimento; E - enchimento de sementes.

Os componentes avaliados da parte aérea das plantas foram a área foliar e os teores de matéria seca total, no pendão, na lâmina foliar, na espiga com palha e no colmo com bainhas, seguindo metodologia proposta por CARLETON \& FOOTE (1975). Também foram avaliadas a produção de grãos e a qualidade 
fisiológica das sementes, essa por meio da porcentagem de germinação (BRASIL, 1980) e pelo vigor, que foi avaliado por meio dos métodos do envelhecimento acelerado (MARCOS FILHO et al., 1987), do teste do frio e da condutividade elétrica (AOSA, 1983).

\section{RESULTADOS E DISCUSSÃO}

Na Tabela 4, são apresentados os resultados obtidos da área foliar e da matéria seca da parte aérea das plantas, em relação a três períodos de irrigação. As plantas submetidas à irrigação durante todo o ciclo (I1), geralmente, foram as que apresentaram maiores médias de área foliar e de acúmulos de matéria seca. Essa diferença de área foliar em função do período de irrigação pode ser explicada pela diminuição da elongação foliar, em que a menor área foliar proporciona menor distribuição de fotossintetizados para os tecidos vegetativos, ocorrendo menor taxa de fotossíntese líquida (EMBRAPA, 1993).

TABELA 4. Médias da área foliar e da matéria seca total de colmos, folhas, espiga e pendão de plantas de milho submetidas a três regimes de água (I1, I2, I3) durante o ciclo da cultura.

\begin{tabular}{|c|c|c|c|c|c|c|}
\hline \multirow{2}{*}{ Período de Irrigação } & \multirow{2}{*}{$\begin{array}{l}\text { Área Foliar } \\
\left(\mathrm{cm}^{2}\right)\end{array}$} & \multicolumn{5}{|c|}{ Matéria Seca $(\mathrm{g})$} \\
\hline & & Folhas & Colmo & Espiga & Pendão & Total \\
\hline I1 - durante todo o ciclo & $35,24 a$ & $22,61 \mathrm{a}$ & $45,38 \mathrm{a}$ & $68,48 \mathrm{a}$ & $5,17 \mathrm{a}$ & $90,43 a$ \\
\hline I2 - após emissão da $12^{\mathrm{a}}$ folha & $27,55 \mathrm{~b}$ & $16,17 \mathrm{~b}$ & $34,14 \mathrm{~b}$ & $67,80 \mathrm{a}$ & $5,44 \mathrm{a}$ & $79,61 \mathrm{~b}$ \\
\hline I3 - até 20 dias após o florescimento & $31,75 \mathrm{ab}$ & $19,51 \mathrm{ab}$ & $39,99 \mathrm{ab}$ & $56,19 \mathrm{a}$ & $4,28 \mathrm{a}$ & $83,69 \mathrm{ab}$ \\
\hline
\end{tabular}

Médias seguidas da mesma letra na coluna não diferem entre si, pelo teste de Tukey, a 5\% de probabilidade.

Nas Tabelas 5 e 6, observa-se que, nas diversas avaliações, as plantas que sofreram deficiência hídrica até o estádio de desenvolvimento da $12^{\underline{a}}$ folha (I2), apresentaram menor área foliar e menor teor de matéria seca de folhas em relação às submetidas à deficiência hídrica após 20 dias do florescimento (I3). Esses resultados concordam com YANG et al. (1993) e EMBRAPA (1993), os quais relatam que a deficiência hídrica no período vegetativo no milho diminui o crescimento das plantas pela menor disponibilidade de $\mathrm{CO}_{2}$, limitando os processos de elongação celular.

Na quinta avaliação, a diminuição da área foliar somente para as plantas das parcelas com irrigação I2, pode ter sido provocada por uma antecipação da senescência das folhas no ciclo da cultura. JONES et al. (1981) consideram o desenvolvimento fenológico mais rápido como um mecanismo de resistência utilizado pela planta em estresse hídrico.

TABELA 5. Valores obtidos em cinco avaliações de área foliar de plantas de milho, submetidas a três regimes de irrigação (I1, I2, I3).

\begin{tabular}{lccccc}
\hline \multirow{2}{*}{ Período de Irrigação } & \multicolumn{5}{c}{ Área Foliar $\left(\mathrm{cm}^{2}\right)$} \\
\cline { 2 - 6 } & $1^{\mathrm{a}}\left(23 \mathrm{dae}^{*}\right)$ & $2^{\mathrm{a}}(39 \mathrm{dae})$ & $3^{\mathrm{a}}(51 \mathrm{dae})$ & $4^{\mathrm{a}}(67 \mathrm{dae})$ & $5^{\mathrm{a}}(107 \mathrm{dae})$ \\
\hline I1 - durante todo o ciclo & $2,60 \mathrm{a}$ & $10,25 \mathrm{a}$ & $52,26 \mathrm{a}$ & $53,02 \mathrm{a}$ & $56,88 \mathrm{a}$ \\
$\mathrm{I} 2$ - após emissão da 12 & $1,38 \mathrm{a}$ & $6,05 \mathrm{a}$ & $39,54 \mathrm{~b}$ & $46,80 \mathrm{~b}$ & $44,97 \mathrm{~b}$ \\
$\mathrm{I} 3$ - até 20 dias após o florescimento & $2,10 \mathrm{a}$ & $12,09 \mathrm{a}$ & $45,38 \mathrm{ab}$ & $48,55 \mathrm{ab}$ & $50,61 \mathrm{ab}$ \\
\hline
\end{tabular}

*dae - dias após emergência. Médias seguidas da mesma letra na coluna não diferem entre si, pelo teste de Tukey, a 5\% de probabilidade. 
TABELA 6. Valores obtidos em cinco avaliações de matéria seca (m.s.) de folhas de plantas de milho, submetidas a três regimes de irrigação (I1, I2, I3).

\begin{tabular}{lccccc}
\hline \multirow{2}{*}{ Período de Irrigação } & \multicolumn{5}{c}{ Matéria Seca de Folhas $(\mathrm{g})$} \\
\cline { 2 - 6 } & $1^{\mathrm{a}}(23$ dae*) & $2^{\mathrm{a}}(39$ dae $)$ & $3^{\mathrm{a}}(51 \mathrm{dae})$ & $4^{\mathrm{a}}(67$ dae $)$ & $5^{\mathrm{a}}(107$ dae $)$ \\
\hline I1 - durante todo o ciclo & $0,75 \mathrm{a}$ & $4,18 \mathrm{a}$ & $28,25 \mathrm{a}$ & $34,40 \mathrm{a}$ & $45,49 \mathrm{a}$ \\
I2 - após emissão da 12 & $0,44 \mathrm{a}$ & $2,11 \mathrm{a}$ & $20,17 \mathrm{a}$ & $26,31 \mathrm{~b}$ & $31,82 \mathrm{~b}$ \\
I3 - até 20 dias após o florescimento & $0,83 \mathrm{a}$ & $5,27 \mathrm{a}$ & $24,58 \mathrm{a}$ & $31,21 \mathrm{ab}$ & $35,67 \mathrm{~b}$ \\
\hline
\end{tabular}

*dae - dias após emergência. Médias seguidas da mesma letra na coluna não diferem entre si, pelo teste de Tukey, a 5\% de probabilidade.

Nas Tabelas 7 e 8, observa-se que, nos períodos vegetativos (primeira, segunda e terceira avaliações) e de florescimento (quarta avaliação), os menores valores de matéria seca total e de colmo foram obtidos nas parcelas em que se aplicou o tratamento I2 (irrigação após a emissão da $12^{-}$folha). No período considerado de enchimento de sementes ( $5^{\text {a }}$ avaliação), somente as plantas das parcelas com irrigação I3 não aumentaram sua matéria seca de colmo. Considera-se que, nessas plantas, a suspensão da irrigação aos 20 dias após o florescimento provocou as diminuições do potencial hídrico e da área foliar, proporcionando menor distribuição de fotossintetizados para os tecidos vegetativos, ocorrendo menor taxa de fotossíntese líquida, de forma semelhante ao identificado por FANCELLI \& DOURADO-NETO (2000).

TABELA 7. Valores obtidos em cinco avaliações de matéria seca total de plantas de milho, submetidas a três regimes de irrigação (I1, I2, I3).

\begin{tabular}{lccccc}
\hline \multirow{2}{*}{ Período de Irrigação } & \multicolumn{5}{c}{ Matéria Seca Total $(\mathrm{g})$} \\
\cline { 2 - 5 } & $1^{\mathrm{a}}(23$ dae* $)$ & $2^{\mathrm{a}}(39$ dae $)$ & $3^{\mathrm{a}}(51$ dae $)$ & $4^{\mathrm{a}}(67$ dae $)$ & $5^{\mathrm{a}}(107$ dae $)$ \\
\hline I1 - durante todo ciclo & $1,08 \mathrm{a}$ & $5,75 \mathrm{a}$ & $60,75 \mathrm{a}$ & $128,56 \mathrm{a}$ & $291,00 \mathrm{a}$ \\
$\mathrm{I} 2$ - após a emissão da $12^{\mathrm{a}}$ folha & $0,62 \mathrm{a}$ & $2,66 \mathrm{a}$ & $36,63 \mathrm{a}$ & $120,07 \mathrm{a}$ & $238,05 \mathrm{~b}$ \\
I3 - até 20 dias após o florescimento & $1,10 \mathrm{a}$ & $7,38 \mathrm{a}$ & $50,61 \mathrm{a}$ & $129,44 \mathrm{a}$ & $229,92 \mathrm{~b}$ \\
\hline *dae - dias após emergência. Médias seguidas da mesma letra na coluna não diferem entre si, pelo teste de Tukey, a 5\% de \\
probabilidade.
\end{tabular}

TABELA 8. Valores obtidos em cinco avaliações de matéria seca de colmos de plantas de milho, submetidas a três regimes de irrigação (I1, I2, I3).

\begin{tabular}{lccccc}
\hline \multirow{2}{*}{ Período de Irrigação } & \multicolumn{5}{c}{ Matéria Seca de Colmos $(\mathrm{g})$} \\
\cline { 2 - 6 } & $1^{\mathrm{a}}\left(23\right.$ dae $\left.^{*}\right)$ & $2^{\mathrm{a}}(39 \mathrm{dae})$ & $3^{\mathrm{a}}(51$ dae $)$ & $4^{\mathrm{a}}(67$ dae $)$ & $5^{\mathrm{a}}(107 \mathrm{dae})$ \\
\hline I1 - durante todo o ciclo & $0,33 \mathrm{a}$ & $1,58 \mathrm{a}$ & $32,51 \mathrm{a}$ & $78,42 \mathrm{a}$ & $114,09 \mathrm{a}$ \\
I2 - após a emissão da 12 & $0,18 \mathrm{a}$ & $0,55 \mathrm{a}$ & $16,47 \mathrm{~b}$ & $62,58 \mathrm{~b}$ & $90,94 \mathrm{~b}$ \\
I3 - até 20 dias após o florescimento & $0,27 \mathrm{a}$ & $2,11 \mathrm{a}$ & $26,03 \mathrm{ab}$ & $84,72 \mathrm{a}$ & $86,82 \mathrm{~b}$ \\
\hline
\end{tabular}

*dae - dias após emergência. Médias seguidas da mesma letra na coluna não diferem entre si, pelo teste de Tukey, a 5\% de probabilidade.

Para os teores de matéria seca de espiga e de pendão, as plantas não apresentaram diferença significativa entre os regimes de irrigação (Tabela 9). Entretanto, na primeira avaliação, os maiores teores foram encontrados nas parcelas com irrigação I2 pelo mesmo motivo da diminuição da área foliar explicado anteriormente, ou seja, a ocorrência de um desenvolvimento fenológico mais rápido da planta (JONES et al., 1981).

Os resultados de produção de grãos são apresentados na Tabela 10, sendo os maiores valores obtidos em condições de irrigação total (I1), os quais não se diferenciaram dos valores obtidos em condições de irrigação até 20 dias após o florescimento (I3). ECK (1986), estudando a deficiência hídrica em experimento cujas condições foram semelhantes a I1 e I3, também não identificou diferença na produção de grãos. 
TABELA 9. Valores obtidos em duas avaliações de matéria seca de espiga e de pendão de plantas de milho, submetidas a três regimes de irrigação (I1, I2, I3).

\begin{tabular}{lcccc}
\hline \multirow{2}{*}{ Período de irrigação } & \multicolumn{2}{c}{ Matéria Seca de Espigas $(\mathrm{g})$} & \multicolumn{2}{c}{ Matéria Seca de Pendão $(\mathrm{g})$} \\
\cline { 2 - 5 } & $1^{\mathrm{a}}(67$ dae $)$ & $2^{\mathrm{a}}(107$ dae $)$ & $1^{\mathrm{a}}(67$ dae $)$ & $2^{\mathrm{a}}(107$ dae $)$ \\
\hline I1 - durante todo o ciclo & $9,45 \mathrm{a}$ & $127,38 \mathrm{a}$ & $6,29 \mathrm{a}$ & $4,04 \mathrm{a}$ \\
I2 - após e emissão da 12 ${ }^{\mathrm{a}}$ folha & $24,21 \mathrm{a}$ & $111,38 \mathrm{a}$ & $6,97 \mathrm{a}$ & $3,91 \mathrm{a}$ \\
I3 - até 20 dias após o florescimento & $8,11 \mathrm{a}$ & $104,28 \mathrm{a}$ & $5,41 \mathrm{a}$ & $3,15 \mathrm{a}$ \\
\hline *dae - dias após emergência. Médias seguidas da mesma letra na coluna não diferem entre si, pelo teste de Tukey, a 5\% de \\
probabilidade.
\end{tabular}

TABELA 10. Valores médios de produção de grãos para os três regimes de irrigação.

\begin{tabular}{|c|c|c|}
\hline \multirow{2}{*}{ Período de Irrigação } & \multicolumn{2}{|c|}{ Produção } \\
\hline & kg espiga $^{-1}$ & $\mathrm{~kg} \mathrm{ha}^{-1}$ \\
\hline I1 - durante todo o ciclo & $0,13 \mathrm{a}$ & $5.399 \mathrm{a}$ \\
\hline I2 - após a emissão da $12^{\underline{a}}$ folha & $0,09 \mathrm{~b}$ & $3.914 \mathrm{~b}$ \\
\hline I3 - até 20 dias após o florescimento & $0,10 \mathrm{ab}$ & $5.001 \mathrm{ab}$ \\
\hline
\end{tabular}

Médias seguidas pela mesma letra na coluna não diferem entre si, pelo teste de Tukey, a 5\% de probabilidade.

A menor produção foi obtida quando a deficiência hídrica ocorreu durante o estádio de desenvolvimento vegetativo da planta (I2), embora não tenha sido significativamente diferente da produção obtida quando se utilizou a irrigação I3. Esses resultados refletem os obtidos para área foliar e matéria seca (Tabelas 5; 6; 7 e 8) e, portanto, demonstram um efeito direto da redução de biomassa da planta sobre a produção de grãos.

Resultados semelhantes foram encontrados por YANG et al. (1993), que consideram que a deficiência hídrica durante o período vegetativo do milho, além de diminuir o crescimento vegetativo, prejudica o desenvolvimento reprodutivo, culminando com a redução da produção. Segundo ECK (1986), nessa cultura, a redução na produção é maior quando ocorre a deficiência hídrica durante o período vegetativo do que durante o período de enchimento de grãos; essa cultura, do período de polinização à maturidade, torna-se progressivamente mais tolerante a déficits hídricos.

Em relação aos híbridos avaliados (Tabela 11), o DINA-70 apresentou valores maiores de área foliar, de matéria seca e de produção de grãos. Somente para matéria seca de pendão a diferença foi menor, porém não significativa.

TABELA 11. Médias da área foliar e da matéria seca total, de colmos, de folhas, de espiga e de pendão de plantas e de produção de grãos de dois híbridos de milho submetidos a três regimes de água.

\begin{tabular}{|c|c|c|c|c|c|c|c|c|}
\hline \multirow{2}{*}{ Híbrido } & \multirow{2}{*}{$\begin{array}{c}\text { Área Foliar } \\
\left(\mathrm{cm}^{2}\right)\end{array}$} & \multicolumn{5}{|c|}{ Matéria Seca (g) } & \multicolumn{2}{|c|}{ Produção } \\
\hline & & Total & Colmo & Folhas & Espiga & Pendão & kg por espiga & $\mathrm{kg} \mathrm{ha}^{-1}$ \\
\hline & $29,20 \mathrm{~b}$ & $83,36 \mathrm{~b}$ & $34,31 \mathrm{~b}$ & $18,16 \mathrm{~b}$ & $55,96 \mathrm{~b}$ & $5,14 \mathrm{a}$ & $0,09 \mathrm{~b}$ & $4.210 \mathrm{~b}$ \\
\hline DINA 70 & $33,79 a$ & $90,31 \mathrm{a}$ & $45,37 \mathrm{a}$ & $20,78 \mathrm{a}$ & $72,19 \mathrm{a}$ & $4,78 \mathrm{a}$ & $0,12 \mathrm{a}$ & $5.334 \mathrm{a}$ \\
\hline
\end{tabular}

Médias seguidas da mesma letra na coluna não diferem entre si, pelo teste de Tukey, a 5\% de probabilidade.

Na Tabela 12, são apresentados os resultados de germinação e vigor de sementes. Observa-se que não houve diferenças significativas entre os níveis de irrigação e os híbridos, com todos apresentando alta qualidade fisiológica de sementes. A porcentagem de germinação para os três regimes de irrigação variou de 92 a 95\%, faixa acima dos padrões mínimos exigidos para certificação de sementes, que é de 85\% (MARIANNO, 1991). 
TABELA 12. Valores médios obtidos para o teste padrão de germinação (TPG) e para o vigor, por meio dos testes de envelhecimento acelerado (EA), de frio (TF) e de condutividade elétrica (CE), em função de três regimes de irrigação e dois híbridos.

\begin{tabular}{lcccc}
\hline & \multirow{2}{*}{ TPG $(\%)$} & \multicolumn{3}{c}{ Vigor } \\
\cline { 3 - 5 } & & EA $(\%)$ & TF $(\%)$ & CE $\left(\right.$ umhos cm $\left.^{-1} \mathrm{~g}^{-1}\right)$ \\
\hline I1 - irrigação durante todo o ciclo & $95 \mathrm{a}$ & $92 \mathrm{a}$ & $92 \mathrm{a}$ & $6,0 \mathrm{a}$ \\
I2 - irrigação após emissão da 12 ${ }^{\mathrm{a}}$ folha & $92 \mathrm{a}$ & $88 \mathrm{a}$ & $90 \mathrm{a}$ & $7,6 \mathrm{a}$ \\
I3 - irrigação até 20 dias após o florescimento & $94 \mathrm{a}$ & $88 \mathrm{a}$ & $88 \mathrm{a}$ & $6,9 \mathrm{a}$ \\
\hline Híbrido BR 201 & $95 \mathrm{a}$ & $93 \mathrm{a}$ & $93 \mathrm{a}$ & $6,2 \mathrm{a}$ \\
Híbrido DINA-70 & $93 \mathrm{a}$ & $87 \mathrm{a}$ & $87 \mathrm{a}$ & $7,5 \mathrm{a}$ \\
\hline
\end{tabular}

Médias seguidas pela mesma letra na coluna não diferem entre si, pelo teste de Tukey, a probabilidade 5\%.

Os valores de vigor obtidos pelo teste de condutividade elétrica variaram de 6,0 a 7,6 $\mu \mathrm{mhos} \mathrm{cm}^{-1} \mathrm{~g}^{-1}$, sendo esses valores semelhantes aos obtidos por MARIANNO (1991) e VIEIRA et al. (1992) para sementes consideradas vigorosas. Da mesma forma, os valores obtidos de vigor mostraram-se altos nos testes de envelhecimento acelerado (87 a 93\%) e de frio (87 a 93\%), correspondendo a sementes de alta qualidade fisiológica e concordando com resultados obtidos por ALBUQUERQUE (2000).

Isso mostra que, embora tenha causado reduções na produção, a deficiência hídrica não alterou a qualidade fisiológica de sementes de milho. Esses resultados corroboram colocações de que uma planta sob condições de estresse reduz a sua produção total de sementes, mas mantém a qualidade fisiológica daquelas produzidas.

\section{CONCLUSÕES}

Na cultura do milho, a deficiência hídrica durante o período vegetativo (irrigação após a emissão da $12^{\underline{a}}$ folha) foi a mais prejudicial à cultura e à produção. A condição de deficiência hídrica não afetou a qualidade fisiológica das sementes. O híbrido DINA-70 apresentou melhores resultados para os parâmetros fisiológicos e de produção que o híbrido BR201. O estresse por deficiência hídrica reduziu a produção da planta de milho, mas não afetou a qualidade fisiológica das sementes produzidas.

\section{REFERÊNCIAS BIBLIOGRÁFICAS}

ALBUQUERQUE, M.C.F. Desempenho germinativo e testes de vigor para sementes de girassol, milho e soja semeadas sob condições de estresse ambiental. 2000. 180 f. Tese (Doutorado em Produção e Tecnologia de Sementes) - Universidade Estadual Paulista, Faculdade de Ciências Agrárias e Veterinárias, Jaboticabal, 2000.

AOSA. Association of Official Seed Analysis. Seed vigor testing handbook. Lincoln, 1983. 93 p.

BERGONCI, J.I.; BERGAMASCHI, H; SANTOS, A.O.; FRANÇA, S.; RADIN, B. Eficiência da irrigação em rendimento de grãos e matéria seca de milho. Pesquisa Agropecuária Brasileira, Brasília, v.36, n.7, p.949-56, jul.2001.

BRASIL. Ministério da Agricultura. Regras para análise de sementes. Brasília: DNPV/DISEM, 1980. $188 \mathrm{p}$.

CARLETON, A.E.; FOOTE, W.H. A comparison of methods for estimating total leaf area of barley plants. Crop Science, Madison, v.5, p.603, 1975.

CHOTENA, M.; MAKUS, D.J.; SIMPSON W.R. Effect of water stress on production and quality of sweet corn seed. Journal of American Society of Horticultural Science, Virginia, v.105, n.3, p.289-93, 1980. 
CUNHA, G.R.; BERGAMASCHI, H. Efeito da disponibilidade hídrica sobre o rendimento das culturas. In: BERGAMASCHI (Coord.) Agrometeorologia aplicada à irrigação. Porto Alegre: UFRGS - Ed. Universitária, 1992. p.85-97.

DOORENBOS, J.; PRUITT, W.O. Crop water requirements. Rome: FAO, 1984. 144 p. (Irrigation and Drainage Paper, 24).

ECK, H.V. Effects of water deficits on yield, yield components and water use efficiency of irrigated corn. Agronomy Journal, Madison, v.78, n. 6, p.1035-40, 1986.

EMPRESA BRASILEIRA DE PESQUISA AGROPECUÁRIA. Recomendações técnicas para o cultivo do milho. Brasília: EMBRAPA - Milho, 1993. 204 p.

FANCELLI, A.L.; DOURADO NETO, D. Ecofisiologia e fenologia. In: . Produção de milho.

Guaíba: Agropecuária, 2000. cap.1. p.21-53.

FORNASIERI FILHO, D. A cultura do milho. Jaboticabal: FUNEP, 1992. 273 p.

JONES, M.M.; TURNER, N.C.; OSMOND, C.B. Mechanisms of drought resistance. In: PALEG, L.G.; ASPINALL, D. (Ed.) The physiology and biochemistry of drought resistance in plants. New York: Academic Press, 1981. p.15-37.

JURGENS, S.K.; JOHNSON, R.R.; BOYER, J.S. Dry matter production and translocation in maize subjected to drought during grain fill. Agronomy Journal, Madison, v.70, n. 4, p.678-82, 1978.

MARCOS FILHO, J.; CÍCERO, S.M.; SILVA, W.R. Avaliação da qualidade das sementes. Piracicaba: FEALQ, 1987. 230 p.

MARIANNO, M.I.A. Avaliação qualitativa de sementes de milho durante o beneficiamento com ênfase para danificação mecânica. 1991. 106 f. Dissertação (Mestrado em Fitotecnia) - Universidade São Paulo, Escola Superior de Agricultura “Luiz de Queiroz”, Piracicaba, 1991.

NESMITH, D.S.; RITCHIE, J.T. Short and long term responses of corn to a pre-anthesis soil water deficit. Agronomy Journal, Madison, v.84, n.1, p.107-13, 1992.

SILVA, S.C. Relação entre o tamanho das sementes de milho (Zea Mays L.) com a germinação, o vigor e os componentes da produção de grãos. 2000. 69 f. Dissertação (Mestrado em Produção e Tecnologia de Sementes) - Universidade Estadual Paulista, Faculdade de Ciências Agrárias e Veterinárias, Jaboticabal, 2000.

VIEIRA, R.D.; TEKRONY, D.M.; EGLY, D.B. Effect of drought and defoliation stress on soybean seed germination and vigor. Crop Science, Madison, v.32, n.2, p.471-5, 1992.

YANG, C.M.; FAN, M.J.; HSIANG, W.M. Growth and yield responses of maize (Zea mays L.) to soil water deficits. II - Effects of water deficit timing and strenght. Journal Agricultural Research, Taipei, v.42, n.2, p.173-86, 1993. 